\title{
Fungal endophyte mediated occurrence of seminiferous and pseudoviviparous panicles in Festuca rubra
}

\author{
P. E. Gundel • L. A. Garibaldi • P. R. Wäli • M. Helander • \\ S. Dirihan $\cdot$ K. Saikkonen
}

Received: 31 December 2013 / Accepted: 11 April 2014 / Published online: 26 April 2014

(C) Mushroom Research Foundation 2014

\begin{abstract}
Fungal endophytes are suggested to manipulate host grass reproduction. Using different grass-endophyte combinations in a four year common garden experiment, we show that endophyte can retain control over the reproductive functions of the host. Plants were collected as seeds from two different environments, meadows and riverbanks. Natural endophyte infection $(\mathrm{E}+)$ increased reproductive effort of plants; 13 and $15 \%$ higher proportion of $\mathrm{E}+$ plants produced panicles compared to naturally uninfected (E-) and manipulatively endophyte-infected $(\mathrm{ME}+)$ plants, respectively. Meadoworigin $\mathrm{E}+$ plants produced also higher number of panicles compared to E- in the last two years, and both meadow- and
\end{abstract}

Electronic supplementary material The online version of this article (doi:10.1007/s13225-014-0290-9) contains supplementary material, which is available to authorized users.

P. E. Gundel · K. Saikkonen

MTT Agrifood Research Finland, Department of Plant Production, Jokioinen, Finland

P. E. Gundel

IFEVA-CONICET-Faculty of Agronomy, Buenos Aires University

(UBA), Buenos Aires, Argentina

\section{A. Garibaldi}

Sede Andina, Universidad Nacional de Río Negro (UNRN) and Consejo Nacional de Investigaciones Científicas y Técnicas (CONICET), Mitre 630, CP 8,400, San Carlos de Bariloche, Río Negro, Argentina

P. R. Wäli

Department of Biology, University of Oulu, Oulu, Finland

M. Helander $\cdot$ S. Dirihan

Section of Ecology, Department of Biology, University of Turku, Turku, Finland

P. E. Gundel $(\bowtie)$

MTT Agrifood Research Finland, Plant Production Research,

31600 Jokioinen, Finland

e-mail: gundel@agro.uba.ar riverbank-origin $\mathrm{ME}+$ plants produced higher number of panicles compared to ME- plants in most of the years. Pseudovivipary was recorded in $5 \%$ of the plants each year. Pollen limitation appears not to induce pseudovivipary. Both $\mathrm{E}+$ and $\mathrm{ME}+$ plants produced higher number of seminiferous panicles compared to E- and ME- plants. The higher proportion of pseudoviviparism in $\mathrm{ME}+$ plants compared to $\mathrm{E}+$, Eand ME- plants from meadows suggests specific genotypegenotype cross-talk between endophyte and grass. Pseudovivipary was affected by year and primarily explained by plant reproductive effort since most vigorous plants produced more pseudoviviparous panicles. We propose that endophytes can promote host grass reproduction in a habitatspecific manner and depending on genetic compatibility between partners. However, reproductive behavior depended on maternal habitat and the annual environmental conditions highlighting the importance of long-term experiments to estimate the effects of endophytes on host plant ecology.

Keywords Grass-endophyte interaction - Systemic fungal endophytes - Symbiosis - Seminiferous panicles . Pseudovivipary

\section{Introduction}

The importance of symbiotic interactions between plants and microorganisms in biomass partitioning to plant growth and reproduction has been largely ignored (e.g. Tuomi et al. 1983; Obeso 2002; Poorter et al. 2012). Here, we focus on the effects of epichloid fungal endophytes (Family Clavicipitaceae) on the reproductive behavior of host grasses. The epichloid endophytes form systemic and species-specific symbiotic associations with certain cool-season grasses of the subfamily Pooideae (Saikkonen et al. 1998; Clay and Schardl 2002). In the symbiosis, hyphae of a single fungal individual grows 
throughout the above-ground plant parts allowing the vertical transmission of the fungus from mother plants to offspring (Clay and Schardl 2002; Tadych et al. 2012). In its extreme form of the symbiosis, Neotyphodium endophytes have entirely lost their ability for sexual reproduction and contagious spread (Leuchtmann et al. 1994; Clay and Schardl 2002). Because the fitness of the fungus is highly dependent on the fitness of the host plant, these endophytes are often viewed as plant mutualists that are 'trapped pathogens' and 'slaves' to the host plant (Saikkonen et al. 2004). However, recently Saikkonen et al. (2004) suggested that these endophytes can retain control over host plant functions through several mechanisms. For example, endophytes can modulate host plant reproduction by increasing the proportional allocation to seed or tiller production, or inducing the seed germination before they are detached from the mother plant (vivipary) and (or) development of plantlets from vegetative buds that replace the flower (pseudovivipary) of the host (Faeth and Sullivan. 2003; Saikkonen et al. 2004).

In this study we use the symbiosis between Festuca rubra s.l. L. (red fescue) and the fungal endophyte Epichloë festucae as model system to study the effects of the symbiont on host plant reproduction. The fungus is vertically transmitted but able to contiguously spread by sexual ascospores. The ascospores are produced in sexual structures (stromata) castrating grass inflorescences known as the choke disease in plant pathology. However, the fungus is observed to be primarily nonpathogenic in the field (Schardl 2001; Zabalgogeazcoa et al. 2006; Wäli et al. 2007). Because the symbiosis is based on mutual exploitation, the nonpathogenic symbiosis is context dependent varying from antagonistic to mutualistic depending on resource availability and biological interactions (Ahlholm et al. 2002; Clay and Schardl 2002; Faeth 2002; Faeth and Sullivan 2003; Zabalgogeazcoa et al. 2006; Gundel et al. 2011; Saikkonen et al. 2013a). The question is whether the fungus is a passive 'hitchhiker' in the host population or an active participant manipulating the host resource allocation to promote its own fitness.

Several empirical studies suggest that endophytes can affect host plant reproduction (e.g., Vila-Aiub et al. 2005; Wäli et al. 2008; Saikkonen et al. 2010; Gundel et al. 2013a,b; Gorischek et al. 2013). Vertical transmission via host seeds and vegetative tillers are the dispersal avenues of the fungus (Saikkonen et al. 2002). However, vertical transmission may destabilize the endophyte-grass interaction and potentially lower the frequencies of endophyte infected plants in the outcrossing host population because sexual reproduction of the host increases the risk of genetic mismatch between the asexual fungus and the outcrossing host grass (Saikkonen et al. 2004). Thus, to avoid genetic mismatch and following suppressed seedling establishment, the fungus should promote (1) asexual reproduction over sexual reproduction, (2) self-fertilization, and (3) the production of ovaries rather than pollen in host plant reproduction.
Consequences to the endophyte and the host plant can be mutually beneficial but dependent on the fitness of the host seedlings and vegetative tillers determined by the success of the phenotype of fungus-host unit. Vegetative reproduction provides an opportunity for extensive multiplication of genetically identical repetitive units in the habitat, and may promote plant establishment (Harper 1977; Obeso 2002). In fact, pseudovivipary which is an asexual reproductive strategy consisting in growing leafy plantlets instead of sexuallyproduced seeds, is suggested to be advantageous to grasses by enabling particularly late-flowering species to cope with the short growing seasons in strongly seasonal arctic, alpine and arid regions that are suboptimal for reproduction by seedborne offspring (Moore and Doggett 1976; Harmer and Lee 1978a,b; Beetle 1980; Lee and Harmer 1980; Heide 1988, 1989; Molau 1993; Elmqvist and Cox 1996; Sarapul'tsev 2001). That is because the plantlets are autotrophic, relatively large and thus vigor, when they reach the soil (Harmer and Lee 1978a,b; Clay 1986; Vega and Rúgolo de Agrasar 2006; Pierce et al. 2003). Although pseudovivipary is partially genetically controlled, in many plant species pseudovivipary appears to be occasional and labile depending on abiotic and biotic environmental factors; pseudovivipary has been detected to vary among species, populations and individual plants, and plants can often display variable proportions of both, seminiferous inflorescences and pseudoviviparous panicles (Aiken et al. 1988; Heide 1988, 1990, 1994; Elmqvist and Cox 1996; Chiurugwi et al. 2011).

In a four year common garden experiment we examined the relative importance of systemic and vertically transmitted endophyte infection and maternal effects on host grass reproduction by seeds, seminiferous inflorescences and pseudoviviparous panicles. In order to understand the potential adaptive responses to endophyte infection and the maternal environments (Mosseau and Fox 1998; Saikkonen et al. 2010), we collected both endophyte infected and uninfected Festuca rubra plants from meadows and river banks in subarctic Finland. Based on literature, we assume that endophyte infection promotes plant reproduction in general (Ahlholm et al. 2002; Saikkonen et al. 2010) and red fescue is strictly outcrossing (Harberd 1961). In addition to naturally endophyte-infected plants (E+) and naturally uninfected plants (E-), we also used manipulatively endophyte-infected $(\mathrm{ME}+)$ and uninfected (ME-) plants in order to experimentally test the hypothesis of genetic mismatch between the asexual fungus and the outcrossing host grass (Saikkonen et al. 2004). If the hypothesis holds true, E+ plants should show higher investment to pseudovivipary than $\mathrm{ME}+$ plants to avoid genetic mismatch in their offspring. Because self-pollination should reduce the risk of incompatible combinations, thereby promoting the persistence of successful host-fungus combinations in old established populations, we also tested the occurrence of self-pollination. 


\section{Material and methods}

Plant material and endophyte infection treatments

Festuca rubra L. sensu lato (red fescue) is a native perennial grass in Europe having importance as food source for native fauna and managed grazers. Because it is commonly used in turf grass mixtures, it has importance when developing new cultivars in grass breeding programmes. F. rubra belongs to the fine fescue complex that inhabits a wide range of environments across the latitudes from boreal to arctic regions in the northern hemisphere. Fine fescues can be divided into two main complex groups of species, the $F$. rubra and $F$. ovina aggregates. Although classifying species between these two groups is generally clear, close morphological resemblance makes species often unidentifiable within aggregates. Because of detected great phenotypic variability within the species they are subdivided into subspecies and (or) ecotypes according to their morphological characters (Aiken et al. 1988; Jauhar 1993).

We selected the F. rubra aggregate as a model system because of the following four reasons. First, taxonomy of F. rubra aggregate is largely unclear (see e.g. Huff and Palazzo 1998). Plants falling into morphologically distinguishable categories often are inconsistently classified as both species and subspecies (Aiken et al. 1988). (Sub)species show extensive hybridization, potentially resulting in observed natural polyploids (e.g. F. rubra ssp. rubra both either $6 \times=42$ or $8 \times=$ 56, F. rubra ssp. arctica $6 \times=42$, and F. rubra ssp. arenaria $6 \times=56)$. Interfertile plants exhibit striking morphological variation (Jauhar 1993). Hybridization between F. rubra aggregate with other fine fescues should not be ruled out in joint growing sites either. Second, although F. rubra primarily produces seminiferous inflorescences, it occasionally produces also pseudoviviparous inflorescences whose ecological and evolutionary importance is largely ignored (Aiken et al. 1988; Heide 1990, 1994). Third, F. rubra aggregate is well known for occasionally high frequencies of systemic fungal endophytes (Tredway et al. 1999; Saikkonen et al. 2000; Bazely et al. 2007; Granath et al. 2007; Zabalgogeazcoa et al. 2006; Wäli et al. 2007) - plant associated fungi that are suggested to expand distribution range of the host grass (Clay and Schardl 2002). Fourth, F. rubra is widely used in commercial seed mixtures with numerous registered cultivars and with several non-native fescue species in Finland, potentially obscuring species boundaries through unconventional interspecific hybridization.

We collected seeds from a total of 110 wild "parental" plants in 6 meadow populations ( 68 plants) and in 4 riverbank populations (42 plants) of subarctic river valleys in northernmost Finland in 2000 (Saikkonen et al. 2010). The infection status of these plants was observed through microscope examination of seeds (Saha et al. 1988). Eighty seven maternal plants producing either $\mathrm{E}+$ (naturally endophyte-infected) or
E- (naturally uninfected) progenies were assigned to the endophyte manipulations. Manipulatively endophyte-free plants (ME-) were generated by removing the endophyte from $\mathrm{E}+$ seeds with heat treatment while manipulatively endophyteinfected plants $(\mathrm{ME}+)$ were generated by inoculating Epichloë festucae hyphae of previously isolated fungi into E- seedlings (for details, see Saikkonen et al. 2010). Isolated fungi were inoculated into seedlings from the same grass population (See methodological details in Williams et al. 1984; Latch and Christensen 1985; Saikkonen et al. 2010).

The common garden experiment

Naturally and manipulatively infected and uninfected (i.e., E+, E-, ME+ and ME-) F. rubra plants were transplanted from greenhouse to common garden at Ruissalo Botanical Garden, University of Turku in 2003 (in total 679 plants). The experiment was conducted using a randomized block design consisting of 19 blocks in which 134 and $72 \mathrm{E}+, 184$ and $139 \mathrm{E}-, 39$ and $35 \mathrm{ME}+$ and 35 and $41 \mathrm{ME}-$ seedlings of 75 maternal plants originating from meadows (48 plants) or river banks (27 plants), respectively, were randomly arranged $30 \mathrm{~cm}$ apart each other. Before transplantation, vegetation was removed and a $50 \mathrm{~cm}$ layer of soil was replaced by sand, and the area was fenced to prevent large vertebrates (e.g., rabbits, deer) from browsing the plants. The plants were watered during the first month to secure their establishment. Thereafter the area was untouched except hand-weeding.

During a four years experimental period, we recorded the occurrence of seminiferous and pseudo-viviparous panicles produced by each plant to test the relative importance of maternal habitat, transgenerational effects (inc. genetic and/ or maternal effects) and endophyte infection to plant reproduction strategies. In addition to counting the number of seminiferous panicles, we also tested the occurrence of selfpollination by recording the number of seeds in panicles which were either open to cross-pollination or prevented from cross-pollination in 2004. Two panicles in plants with four or more panicles were individually closed in waxed bags and the number of seeds was counted in unbagged and bagged plants. In 2005 we counted beside the number of panicles also the seed number of the plants. In 2013, we determined the ploidy level of 133 plants (56 E-, $37 \mathrm{E}+, 24 \mathrm{ME}-$ and $15 \mathrm{ME}+$ ) by flow cytometry (FCM) (Dirihan et al. 2013). Based on the suggested concurrent latitudinal gradients of polyploidy and pseudovivipary (Aiken et al. 1988; Molau 1993; Brochmann et al. 2004), we predict that pseudoviviparous panicles are produced by plants with higher copies of chromosomes.

Statistical analysis

We estimated generalized linear mixed-effects models to analyze the effects of systemic, vertically transmitted endophyte 
infections (endophyte infected and uninfected), the nature of infection (natural or manipulated), maternal habitat of plant (meadow or river bank), year $(2005,2006,2007,2008)$ and their interactions, as fixed effects, on (1) host grass reproduction (panicles produced or not), (2) the production of pseudoviviparous panicles in reproducing plants (yes/no), and (3) the number of strictly sexually reproducing panicles in reproductive plants. The first two variables were analyzed using binomial error distribution (logit link) whereas the number of strictly sexually reproducing panicles were analyzed using a Poisson error distribution (log link, residuals showed no overdispersion). The number of seminiferous panicles was used as a covariate in analyzing whether the plants produced pseudoviviparous panicles. All models included two randomintercept sub-models, one for blocks as random factors, and the other one for individuals nested within mother plants nested within populations. These analyses also accounted for the repeated measurements across years of the same individuals.

Among the three common and accepted statistical inference frameworks (Bayesian, Frequentists, and Multimodel Inference), we choose Multimodel Inference (Burnham et al. 2011). We do not present $P$ values, because it is not recommended to mix different statistical frameworks (Burnham et al. 2011). We used AIC to select best-fitting models for all combinations of fixed-effect variables. AIC values were obtained based on maximum-likelihood estimates of regression coefficients, because models differed in the fixed structure but shared the same random structure (random intercepts), whereas parameter estimates for final models presented in figures were obtained using the restricted maximum likelihood method, as recommended by Zuur et al. (2009). Given the large number of plants, no correction was needed for small samples, AICc (Johnson and Omland 2004), and this correction showed no clear improvement in simulation studies despite low ratio of independent observations to estimated parameters
(Richards 2005). Models were estimated using lmer function of the lme4 package (Bates, Maechler, and Bolker 2011) in the R software (R Development Core Team 2011), and AIC and Akaike's weight for each model of all possible models based on different combinations of the predictor variables were obtained with the dredge function of the MuMIn package (Barton 2012) in the R software. All statistical results are in Supplementary material.

\section{Results}

Reproduction strategy of plants

The endophyte, nature of infection (natural (E+ and E-) vs. manipulative (ME+ and ME-) infection) and maternal habitat of plants affected plant reproduction strategies (Fig. 1). Plant investment to reproduction varied also among years (Fig. 1). Endophyte infection promoted plant investment to reproduction, but only if they were naturally endophyte infected $(\mathrm{E}+)$ (Fig. 1). The tendency of $\mathrm{E}+$ to present more reproductive plants than E-appeared the same for plants originally collected from both meadows (14\% higher) and river banks (10\% higher). However, this result was not observed when manipulatively endophyte infected plants (ME+: $34 \%$ vs E-: $36 \%$ ) or manipulatively endophyte free plants (ME-: $36 \%$ vs E-: $36 \%$ ) are compared to natural uninfected plants across years and habitats. In contrast, slightly higher proportion of MEplants originally from meadows produced panicles compared to $\mathrm{ME}+$, and higher and lower proportion of $\mathrm{ME}+$ plants originally from river banks reproduced in 2005 and 2008, respectively (Fig. 1).

In reproducing plants, natural infection by endophyte increased the number of panicles in meadow-origin plants in the last two years of experiment (2007 and 2008) (Fig. 2). Similarly, both meadow- and river bank-origin ME+ plants

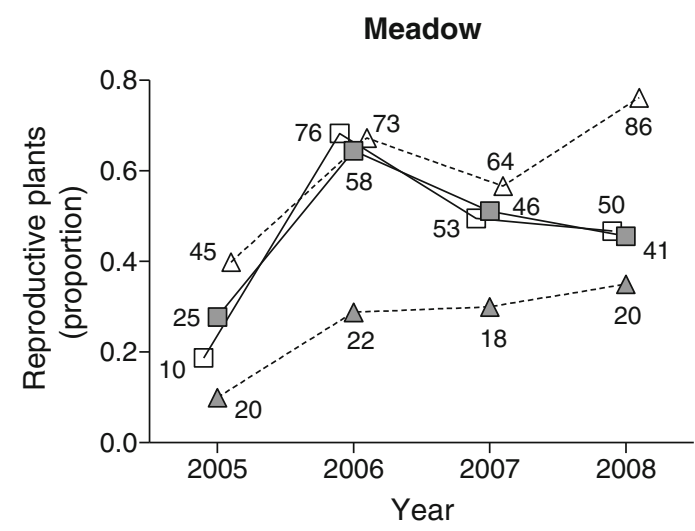

Fig. 1 Proportion of reproductive plants of Festuca rubra (that produced at least one seminiferous panicle) along experimental time (4 years: 2005-2008) for naturally uninfected (E-), naturally infected (E+), manipulatively uninfected (ME-) and manipulatively infected (ME+)
River Bank

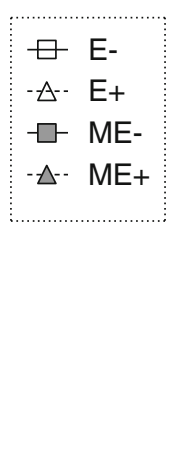

with the fungus endophyte Epichloë festucae from two habitats, meadow and river bank. Symbols, which are slightly moved around year's stick to avoid overlapping, represent the proportions and the numbers beside the symbols are the total reproductive plants in each proportion 

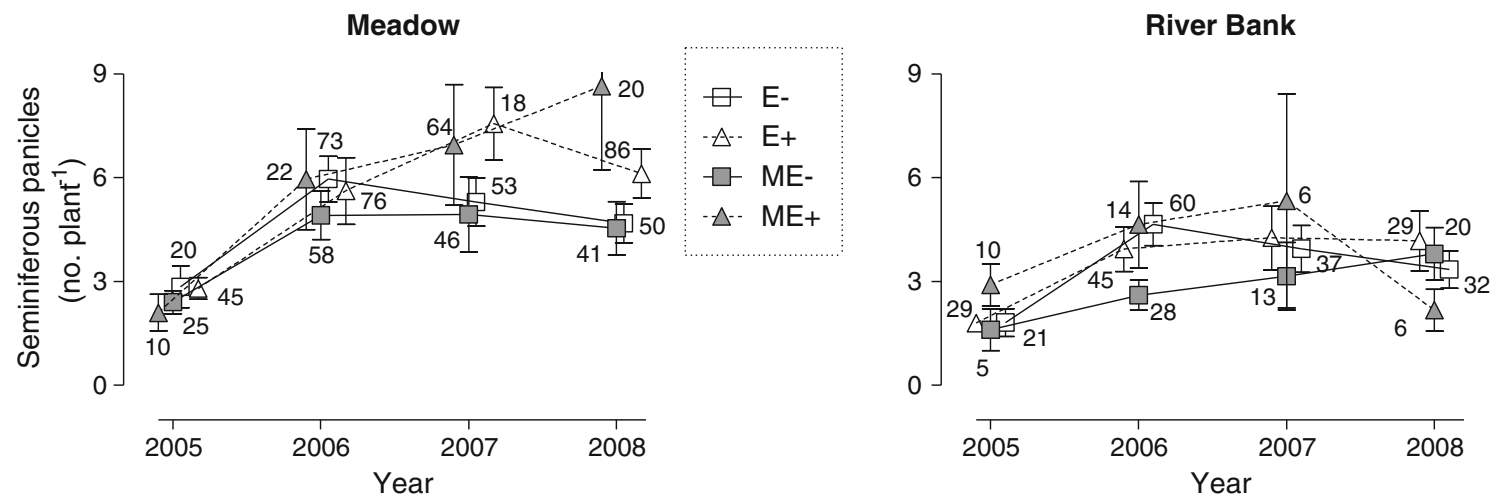

Fig. 2 Number of seminiferous panicles per Festuca rubra plant along experimental time (4 years: 2005-2008) for naturally uninfected (E-), naturally infected $(\mathrm{E}+)$, manipulatively uninfected (ME-) and manipulatively infected $(\mathrm{ME}+)$ with the fungus endophyte Epichloëfestucae, from

produced relatively constantly higher number of panicles compared to ME- plants (meadow-origin: $\mathrm{ME}+=5.91 \% \mathrm{vs}$. $\mathrm{ME}-=4.19 \%$; river bank-origin: $\mathrm{ME}+=3.76 \%$ vs. $\mathrm{ME}-=$ $2.79 \%$ ). In contrast, the number of seminiferous panicles did not vary between $\mathrm{E}+$ and $\mathrm{E}$ - plants collected from riverbanks (Fig. 2).

Of the total 679 plants, 151 produced pseudoviviparous panicles during the four-year study period. In most of the cases, pseudoviviparous plants produced only one pseudoviviparous panicle (Fig. 3). The production of pseudoviviparous plantlets strongly varied among years, and was positively correlated to the number of seminiferous panicles in the plant (Fig. 4). The higher was the number of seminiferous panicles in the plant, the higher was the probability of the plant to produce pseudoviviparous plantlets (Fig. 4). Endophyte infection, the nature of infection (natural or manipulative) or the original habitat of the plant did not

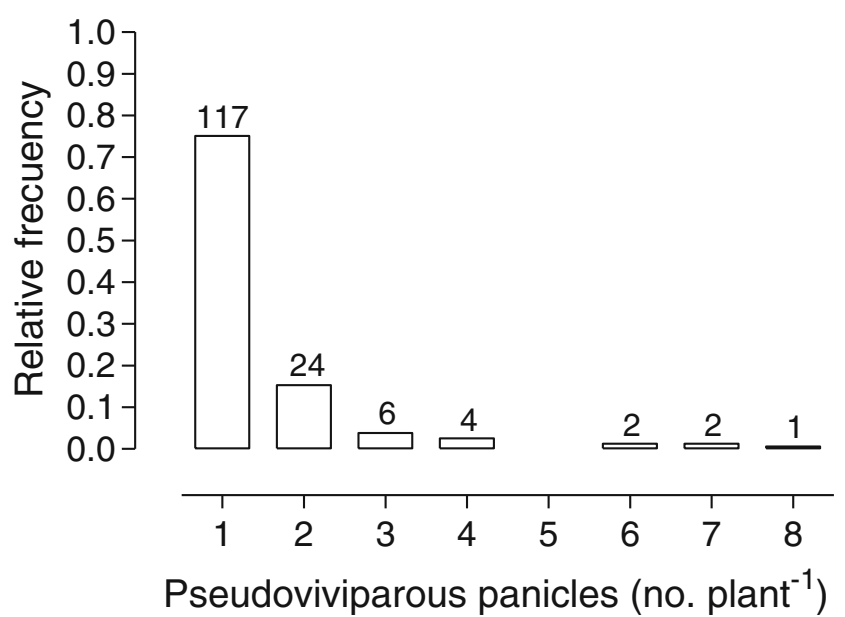

Fig. 3 Relative frequency distribution (histogram) of the number of pseudoviviparous panicles in Festuca rubra plants. It includes all the treatments and the 4 years of experiment (2005-2008). Numbers above the bars are total plants in each category two habitats, meadow and river bank. The symbols, which are slightly moved around year's stick to avoid overlapping, represent average values $( \pm \mathrm{SE}$ ) while the numbers beside the symbols are the number of reproductive plants in each proportion

explain the production of pseudoviviparous panicles (Fig. 5). However, the proportion of pseudoviviparous plants in manipulatively endophyte infected $(\mathrm{ME}+)$ plants collected from meadows was higher than in ME- plants $(\mathrm{ME}+=24 \%$ vs. $\mathrm{ME}-=13 \%$ ) (Fig. 6).

\section{Self-pollination}

In contrast to the presumption that $F$. rubra is strictly cross pollinated, 38 out of 664 bagged panicles produced seeds revealing that self-pollination frequently occur. However, the number of seeds was severely reduced; 26,9 and 3 plants produced only one, two or 3 seeds, respectively. The inhibition of pollination did not induce pseudovivipary (data not shown). Only 10 pseudoviviparous plantlets $(1.5 \%)$ were found in bagged panicles.

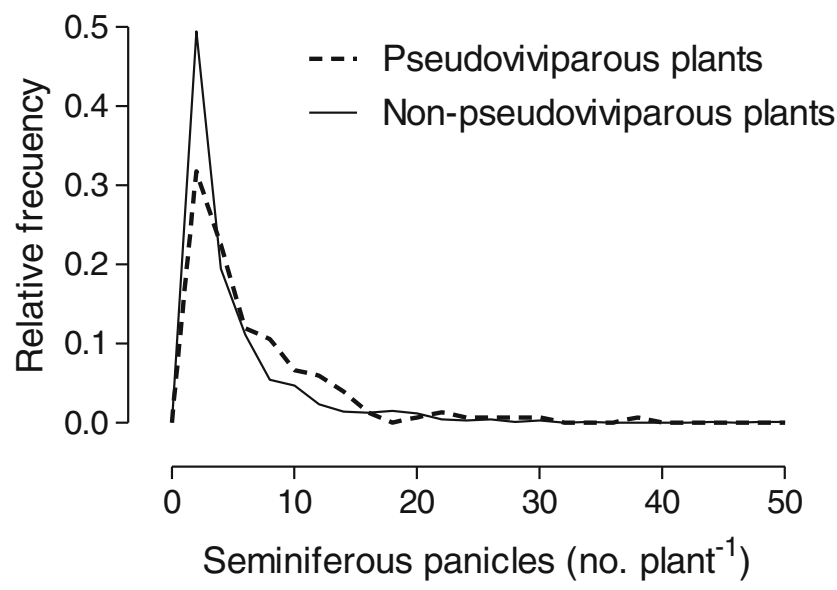

Fig. 4 Relative frequency distribution (histogram) of number of seminiferous panicles for the Festuca rubra plants that produced at least one pseudoviviparous panicle (Pseudoviviparous plants) and plants that did not produce any pseudoviviparous panicle (Non-pseudoviviparous plants) along the experimental time (4 years: 2005-2008) 
Meadow

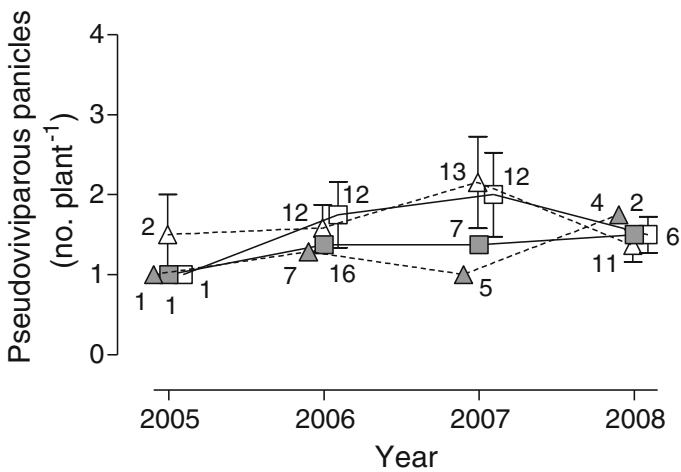

Fig. 5 Number of pseudoviviparous panicles per Festuca rubra plant along experimental time (4 years) for naturally uninfected (E-), naturally infected $(\mathrm{E}+)$, manipulatively uninfected (ME-) and manipulatively infected (ME+) with the fungus endophyte Epichloe festucae, from two

\section{Ploidy level}

All the analyzed 133 plants presented the same ploidy level $(2 \mathrm{n}=6 \times=42)$ (data not shown).

\section{Discussion}

Our results show that endophyte infection, maternal origin, and genetic compatibility between the fungus and the host can control the reproductive functions of F. rubra. Although allocation to reproduction and different reproduction functions appear to be driven interactively by many factors and vary from year to year, on average, higher number of $\mathrm{E}+$ plants invested to panicles during the four years of study than the other categories (E-, ME- and ME+). This supports the general ideas that endophyte infection can promote sexual reproduction of the host plant (Ahlholm et al. 2002; Wäli et al. 2008;
River Bank

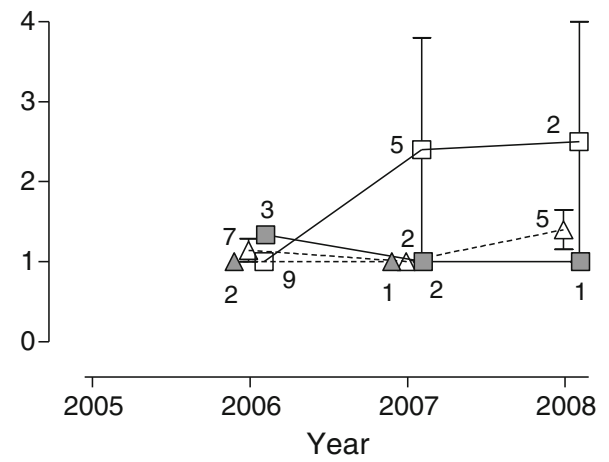

habitats, meadow and river bank. Symbols, which are slightly moved around year's stick to avoid overlapping, represent mean values $( \pm \mathrm{SE})$ and the numbers beside the symbols are the number of plants in each date

Gundel et al. 2013a,b; Gorischek et al. 2013) and that selection for successful host-fungus combinations increases these locally adapted combinations in established grass populations (Gundel et al. 2010; Saikkonen et al. 2010). Benefits from the endophyte to the host appear to be higher in meadows; the higher investment to sexual reproduction in $\mathrm{E}+$ was more pronounced in meadow-origin grasses which may partially explain the higher infection frequencies detected in meadows compared to river banks (Wäli et al. 2007).

Although genetic compatibility appears largely to determine endophyte-grass combinations (Saikkonen et al. 2010) and higher proportion of ME+ meadow-origin grasses produced pseudoviviparous panicles compared to $\mathrm{E}+$ grasses, the increased risk of genetic mismatch between the asexual fungus and the host grass due to sexual reproduction of the host grass appears not to play a major role in driving the host grass reproduction functions. An average of $5.68 \%$ of the plants produced pseudoviviparous panicles each year, but both $\mathrm{E}+$

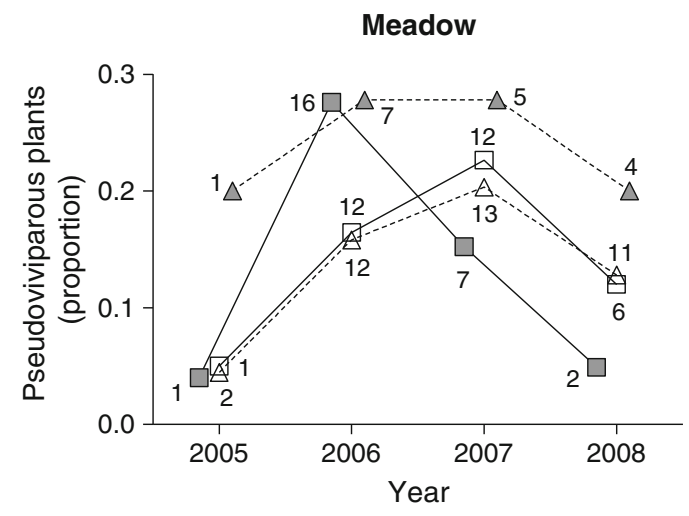

Fig. 6 Proportion of pseudoviviparous Festuca rubra plants (that produced at least one pseudoviviparous panicle) along experimental time (4 years) for naturally uninfected (E-), naturally infected (E+), manipulatively uninfected (ME-) and manipulatively infected (ME+) with the
River Bank

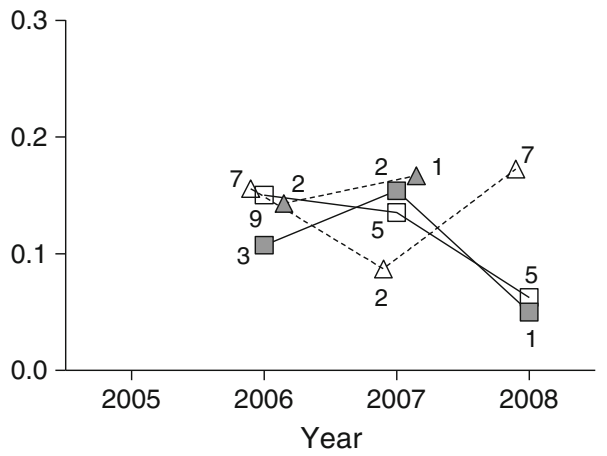

fungus endophyte Epichloë festucae, from two habitats, meadow and river bank. Symbols, which are slightly moved around year's stick to avoid overlapping, represent the proportions and the numbers beside the symbols are the total reproductive plants in each proportion 
and $\mathrm{ME}+$ plants produced higher number of panicles compared to endophyte-uninfected plants and the production of pseudoviviparous plantlets was primarily explained by the production of panicles in general. The most vigorous plants investing substantially to panicles produced also more commonly pseudoviviparous plantlets. Pseudovivipary was, however, more common in $\mathrm{ME}+$ plants than in $\mathrm{E}+$, E- and MEplants suggesting that multifaceted signaling and chemical cross-talk between endophyte and host cells (Hamilton et al. 2012; Saikkonen et al. 2013b) is genotype-genotype-specific.

The detected relatively high frequency of pseudovivipary in F. rubra in our study support the general idea that pseudovivipary provides selective advantage for sparsely distributed and late-flowering plant species in strongly seasonal subarctic areas (Moore and Doggett 1976; Harmer and Lee 1978a,b; Beetle 1980; Lee and Harmer 1980; Heide 1988, 1989; Molau 1993; Elmqvist and Cox 1996; Sarapul'tsev 2001). The production of pseudoviviparous plantlets appeared to occur, however, highly variable and seemingly unpredictable in both endophyte infected and endophyte-free plants irrespectively to the nature of the infection or maternal origin of the grass year after year. This suggests that pseudovivipary in northernmost $F$. rubra populations is induced by changeable biotic or abiotic environmental factors such as animal vectors, drought, flooding, windiness, temperature and showers that determine pollination success of grass flowers and relative dispersal and establishment success of seed-borne and pseudoviviparous offspring of the species (Lee and Harmer 1980; Aiken et al. 1988; Molau 1993; Heide 1994; Elmqvist and Cox 1996; Sarapul'tsev 2001). Pollen limitation appears not to induce pseudovivipary in wind pollinated F. rubra; only 10 pseudoviviparus plantlets were recorded in 664 bagged panicles. Different dispersal success of offsprings produced by seed or pseudovivipaous plantlets do not appear to drive reproduction functions of F. rubra. Viviparous propagules are primarily dispersed by abiotic vectors (Elmqvist and Cox 1996). Thus, high frequency of pseudovivipary should have been detected in riverbank-origin plants if almost annual disturbances due to spring flooding would provide selective advantage by dispersing pseudoviviparous plantlets to favorable environments. In contrast, allocation to pseudovivipary tended to be higher in plants originally collected from meadows which provide better environments for vegetative propagation locally as more stable and fertile environments (Harberd 1961; Wäli et al. 2007; Saikkonen et al. 2010). Thus, we propose that (1) establishment success of offspring is primarily determining the reproductive success of the species, and (2) pseudoviviparous plantlet production would provide higher chances for the offspring establishment in meadows than in riverbanks.

Only a minority of panicles produced pseudoviviparous plantlets suggesting that plant recruitment to the population depends primarily on successful seed germination and seedling establishment. Because the species has no persistent seed bank in northernmost Finland (Wäli et al. 2007), spatial and short-term temporal heterogeneity of environmental conditions have crucial importance. Pseudoviviparous plantlets appear to be 'by-products' of seminiferous panicles mirroring either prevailing or past selection pressures. Genetically well compatible endophyte fungus with its host appears to promote the reproduction of the host grass, and thereby the production of pseudoviviparous plantlets, but reproduction effort depends also on habitat and annual environmental conditions. Thus, long-term experiments are required to reliably estimate the effects of endophytes on host plant population development.

\section{References}

Ahlholm JU, Helander M, Lehtimäki S, Wäli P, Saikkonen K (2002) Vertically transmitted fungal endophytes: different responses of host-parasite systems to environmental conditions. Oikos 99:173-183

Aiken SG, Lefkovitch LP, Darbyshire SJ, Armstrong KC (1988) Vegetative proliferation in inflorescences of red fescue (Festuca rubra s.1, Poaceae). Can J Bot 66(1):1-10

Barton C (2012) MuMIn: Multi-model inference.

Bates D, Maechler M, Bolker B (2011) lme4: Linear mixed-effects models using s4 classes.

Bazely DR, Ball JP, Vicari M, Tanentzap AJ, Bérenger M, Rakocevic T, Koh S (2007) Broad-scale geographic patterns in the distribution of vertically-transmitted, asexual endophytes in four naturallyoccurring grasses in Sweden. Ecography 30:367-374

Beetle AA (1980) Vivipary, proliferation, and phyllody in grasses. J Range Manag 33(4):256-261

Brochmann C, Brysting AK, Alasos IG, Borgen L, Grundt HH, Scheen A-C, Elven R (2004) Polyploidy in arctic plants. Biol J Linn Soc 82: 521-536

Burnham KP, Anderson DR, Huyvaert KP (2011) AIC model selection and multimodel inference in behavioral ecology: some background, observations, and comparisons. Behav Ecol Sociobiol 65:23-35

Chiurugwi T, Beaumont MA, Wilkinson MJ, Battey NH (2011) Adaptive divergence and speciation among sexual and pseudoviviparous populations of Festuca. Heredity 106:854-861

Clay K (1986) Induced vivipary in the sedge Cyperus virens and the transmission of the fungus Balansia cyperi (Clavicipitaceae). Can J Bot 64:2984-2988

Clay K, Schardl CL (2002) Evolutionary origins and ecological consequences of endophyte symbiosis with grasses. Am Nat 160:S99 S127

Dirihan S, Terho P, Helander M, Saikkonen K (2013) Efficient analysis of ploidy levels in plant evolutionary ecology. Caryologia. Int J Cytol Cytosystematics and Cytogenetics 66(3):251-256

Elmqvist T, Cox PA (1996) The evolution of vivipary in flowering plants. Oikos 77(1):3-9

Faeth SH, Sullivan TJ (2003) Mutualistic, asexual endophytes in a native grass are usually parasitic. Am Nat 161:310-325

Faeth SH (2002) Are endophytic fungi generally plant mutualists? Oikos 98:25-36

Gorischek AM, Afkhami ME, Seifert EK, Rudgers JA (2013) Fungal symbionts as manipulators of plant reproductive biology. Am Nat $181: 562-570$

Granath G, Vicari M, Bazely DR, Ball JP, Puentes A, Rakocevic T (2007) Variation in the abundance of fungal endophytes in 
fescue grasses along altitudinal and grazing gradients. Ecography 30:422-430

Gundel PE, Omacini M, Sadras VO, Ghersa CM (2010) The interplay between the effectiveness of the grass-endophyte mutualism and the genetic variability of the host plant in an agronomic context. Evol Appl 3(5-6):538-546

Gundel PE, Zabalgogeazcoa I, Vázquez de Aldana BR (2011) Interaction between plant genotype and the symbiosis with Epichloe fungal endophytes in seeds of red fescue (Festuca rubra). Crop and Pasture Sci 62:1010-1016

Gundel PE, Helander M, Casas C, Hamilton CE, Faeth SH, Saikkonen K (2013a) Neotyphodium fungal endophyte in tall fescue (Schedonorus phoenix): A comparison of three Northern European wild populations and the cultivar Kentucky-31. Fungal Divers 60(1):15-24

Gundel PE, Garibaldi LA, Helander M, Saikkonen K (2013b) Symbiotic interactions as drivers of trade-offs in plants: effects of fungal endophytes on tall fescue. Fungal Divers 60(1):5-14

Hamilton CE, Gundel PE, Helander M, Saikkonen K (2012) Endophytic mediation of reactive oxygen species and antioxidant activity in plants: a review. Fungal Divers 54:1-10

Harberd DJ (1961) Observations on population structure and longevity of Festuca rubra L. New Phytol 60:184-192

Harmer R, Lee JA (1978a) The growth and nutrient content of Festuca vivipara (L.) SM. Plantlets. New Phytol 80(1):99-106

Harmer R, Lee JA (1978b) The germination and viability of Festuca vivipara (L.) SM. Plantlets. New Phytol 81:745-751

Harper JL (1977) Population biology of plants. Academic, London

Heide OM (1988) Environmental modification of flowering and viviparous proliferation in Festuca vivipara and $F$. ovina. Oikos 51(2): $171-178$

Heide OM (1989) Control of fowering and viviparous proliferation in seminiferous and viviparous Arctic populations of two Poa species. Arct Alp Res 21(3):305-315

Heide OM (1990) Primary and secondary induction requirements for flowering of Festuca rubra. Physiol Plant 79(1):51-56

Heide OM (1994) Control of flowering and reproduction in temperate grasses. New Phytol 128(2):347-362

Huff DR, Palazzo AJ (1998) Fine fescue species determination by laser flow cytometry. Crop Sci 38:445-450

Jauhar PP (1993) Cytogenetics of the Festuca-Lolium complex. Relevance to breeding. In: Frankel R, Grossman M, Maliga P (eds.), Monograph on Theoretical and Applied Genetics, vol. 18. Springer-Verlag, Berlin

Johnson JB, Omland KS (2004) Model selection in ecology and evolution. Trends Ecol Evol 19:101-108

Leuchtmann A, Schardl CL, Siegel MR (1994) Sexual compatibility and taxonomy of a new species of Epichloë symbiotic with fine fescue grasses. Mycologia 86:802-812

Latch GCM, Christensen MJ (1985) Artificial infection of grasses with endophytes. Ann Appl Biol 107:17-24

Lee JA, Harmer R (1980) Vivipary, a reproductive strategy in response to environmental stress? Oikos 35(2):254-265

Molau U (1993) Relationships between flowering phenology and life history strategies in Tundra plants. Arct Alp Res 25(4):391-402

Moore DM, Doggett MC (1976) Pseudo-vivipary in Fuegian and Falkland islands grasses. Brit Antarct Surv Bull 43:103-110

Mosseau TA, Fox CW (eds) (1998) Maternal effects as adaptations. Oxford Univ. Press, New York, p 369

Obeso JR (2002) The costs of reproduction in plants. New Phytol 155: 321-348

Pierce S, Stirling CM, Baxter R (2003) Pseudoviviparous reproduction of Poa alpina var. vivipara L. (Poaceae) during long-term exposure to elevated atmospheric $\mathrm{CO}_{2}$. Ann Bot 91(6):613-622

Poorter H, Niklas KJ, Reich PB, Oleksyn J, Poot P, Mommer L (2012) Biomass allocation to leaves, stems and roots: meta analyses of interspecific variation and environmental control. New Phytol 193(1):30-50

R Development Core Team. 2011. R: A language and environment for statistical computing.

Richards SA (2005) Testing ecological theory using the information-theoretic approach: examples and cautionary results. Ecology 86:2805-2814

Saha DC, Jackson MA, Johonson-Cicalese JM (1988) A rapid staining method for detection of endophytic fungi in turf and forage grasses. Phytopathology 78:237-239

Saikkonen K, Faeth SH, Helander M, Sullivan TJ (1998) Fungal endophytes: a continuum of interactions with host plants. Annu Rev Ecol Evol Syst 29:319-343

Saikkonen K, Ahlholm J, Helander M, Lehtimäki S, Niemeläinen O (2000) Endophytic fungi in wild and cultivated grasses in Finland. Ecography 23:360-366

Saikkonen K, Ion D, Gyllenberg M (2002) The persistence of vertically transmitted fungi in grass metapopulations. Proc R Soc B 269:13971403

Saikkonen K, Wäli P, Helander M, Faeth SH (2004) Evolution of endophyte-plant symbioses. Trends Plant Sci 9(6):275-280

Saikkonen K, Wäli PR, Helander M (2010) Genetic compatibility determines endophyte-grass combinations. PLoS ONE 5:e11395. doi:10. 1371/journal.pone.0011395

Saikkonen K, Ruokolainen K, Huitu O, Gundel PE, Piltti T, Hamilton CE, Helander M (2013a) Fungal endophytes help prevent weed invasions. Agric Ecosyst Environ 165(15):1-5

Saikkonen K, Gundel PE, Helander M (2013b) Chemical ecology mediated by fungal endophytes in grasses. J Chem Ecol 39:962-968

Sarapul'tsev IE (2001) The phenomenon of pseudoviviparity in alpine and arctomontane grasses (deschampsia beauv., Festuca L., and Poa L.). Russ J Ecol 32(3):170-178

Schardl CL (2001) Epichloëfestucae and related mutualistic symbionts of grasses. Fungal Genet Biol 33:69-82

Tadych M, Ambrose KV, Bergen MS, Belanger FC, White JF Jr (2012) Taxonomic placement of Epichloë poae sp. nov. and horizontal dissemination to seedlings via conidia. Fungal Divers 54(1):117-131

Tredway LP, White JF Jr, Gaut BS, Reddy PV, Richardson MD, Clarke BB (1999) Phylogenetic relationships within and between Epichlö and Neotyphodium endophytes as estimated by AFLP markers and rDNA sequences. Mycol Res 103(12):1593-1603

Tuomi J, Hakala T, Haukioja E (1983) Alternative concepts of reproductive effort, cost of reproduction, and selection in life-history evolution. Am Zool 23:25-34

Vega AS, Rúgolo de Agrasar ZE (2006) Vivipary and pseudovivipary in the Poaceae, including the first record of pseudovivipary in digitaria (panicoideae: paniceae). S Afr J Bot 72:559-564

Vila-Aiub MM, Gundel PE, Ghersa CM (2005) Fungal endophyte infection changes growth attributes in Lolium multiflorum Lam. Aust Ecol 30:49-57

Wäli PR, Ahlholm JU, Helander M, Saikkonen K (2007) Occurrence and genetic structure of the systemic grass endophyte Epichloë festucae in fine fescue populations. Microb Ecol 53:20-29

Wäli PR, Helander M, Nissinen O, Lehtonen P, Saikkonen K (2008) Endophyte infection, nutrient status of the soil and duration of snow cover influence the performance of meadow fescue in sub-arctic conditions. Grass Forage Sci 63:324-330

Williams MJ, Backman PA, Clark EM, White JF Jr (1984) Seed treatments for control of the tall fescue endophyte Acremonium coenophialum. Plant Dis 68:49-52

Zabalgogeazcoa I, García Ciudad A, Vázquez de Aldana B, García Criado B (2006) Effects of the infection by the fungal endophyte Epichloe festucae in the growth and nutrient content of Festuca rubra. Eur J Agron 24:374-384

Zuur AF, Ieno EN, Walker NJ, Saveliev AA, Smith GM (2009) Mixed effects models and extensions in ecology with R first. Springer, New York 